\title{
Gemcitabine and docetaxel combination chemotherapy for advanced bone and soft tissue sarcomas: protocol for an open-label, non-randomised, Phase 2 study
}

Hitomi Hara ${ }^{1 *}$, Teruya Kawamoto ${ }^{1,2}$, Naomasa Fukase1, Yohei Kawakami ${ }^{1}$, Toshiyuki Takemori ${ }^{1}$, Shuichi Fujiwara ${ }^{1}$, Kazumichi Kitayama', Kotaro Nishida', Ryosuke Kuroda ${ }^{1}$ and Toshihiro Akisue ${ }^{1,3}$

\begin{abstract}
Background: The prognosis of patients with metastatic or advanced sarcomas is poor and there are few options for treatment. Several studies have shown that gemcitabine and docetaxel (GD) combination chemotherapy has antitumor activity against various subtypes of sarcoma. Recently, some studies have shown a favourable outcome for GD combination chemotherapy for relapsed high-grade osteosarcoma and spindle cell sarcoma of bone. If the effectiveness of GD is proven, this will result in new treatment options for advanced bone and soft tissue sarcomas (STS). The aim of this prospective Phase 2 study is to evaluate the efficacy and toxicity of the GD combination in patients with advanced bone sarcomas and STS.

Methods: This is a Phase 2, single-arm, open-label study to investigate the efficacy and safety of combination chemotherapy with GD for advanced bone sarcomas and STS and will enrol 20 patients. The patients will receive gemcitabine $900 \mathrm{mg} / \mathrm{m}^{2}$ on Days 1 and 8 , and docetaxel $70 \mathrm{mg} / \mathrm{m}^{2}$ on Day 8 in 3-week cycles until disease progression or other evidence of treatment failure. The primary aim of this study is to analyse GD's effect on progression-free survival (PFS). The secondary objectives are to analyse treatment efficacy and safety in terms of response rate, tumour control rate, overall survival, and adverse event rate. The length of follow-up will be 5 years.

Discussion: This study will evaluate the efficacy and safety of combination therapy with gemcitabine and docetaxel for bone sarcomas and STS. If this combination proves to be acceptable, it could be used for as second, third, or later line therapy for patients with sarcomas (especially bone sarcomas). In the future, the role of various treatments, including GD therapy, will be clarified for specific subtypes of sarcoma.

Trial registration: This study was registered as UMIN000031004 (University Hospital Medical Information NetworkClinical Trial Registry: UMIN-CTR) on 1 March 12018 and with the Japan Registry of Clinical Trials (jRCT) as jRCTs0511 80042 on 30 January 2019. The posted information will be updated as needed to reflect protocol amendments and study progress.
\end{abstract}

Keywords: Bone and soft tissue sarcomas, Gemcitabine and docetaxel, Phase 2 study

\footnotetext{
*Correspondence: mitohi@med.kobe-u.ac.jp

'Department of Orthopaedic Surgery, Kobe University Graduate School of

Medicine, 7-5-1 Kusunoki-cho, Chuo-ku, Kobe 650-0017, Japan

Full list of author information is available at the end of the article
}

(c) The Author(s). 2019 Open Access This article is distributed under the terms of the Creative Commons Attribution 4.0 International License (http://creativecommons.org/licenses/by/4.0/), which permits unrestricted use, distribution, and reproduction in any medium, provided you give appropriate credit to the original author(s) and the source, provide a link to the Creative Commons license, and indicate if changes were made. The Creative Commons Public Domain Dedication waiver (http://creativecommons.org/publicdomain/zero/1.0/) applies to the data made available in this article, unless otherwise stated. 


\section{Background}

Sarcomas are a heterogeneous group of rare mesenchymal malignant tumours. Chemotherapy has a proven role in the treatment of primary bone sarcomas, including osteosarcoma and Ewing sarcoma. Small round-cell soft tissue sarcomas (STS) such as rhabdomyosarcoma and Ewing sarcoma, which usually occur in children and young adults, are sensitive to chemotherapy. Osteosarcoma and small round-cell sarcomas are therefore treated with chemotherapy in combination with surgery or radiation therapy. The therapy for high-risk patients with high-grade large non-small round-cell STS, which usually occurs in older adults, is usually surgery and chemotherapy. There is no established chemotherapy for bone sarcomas other than osteosarcoma and Ewing sarcoma.

A combination chemotherapy regimen comprising methotrexate, doxorubicin, and cisplatin (MAP) is used for osteosarcoma, whereas regimens including vincristine, doxorubicin, ifosfamide, and actinomycin D (VAIA) or vincristine, doxorubicin, and cyclophosphamide plus ifosfamide and etoposide (VDC-IE) are used for Ewing sarcoma. Vincristine, doxorubicin, and cyclophosphamide (VAC) is used for rhabdomyosarcoma and doxorubicin plus ifosfamide for non-round cell STS. Because no standard chemotherapy for bone sarcomas other than osteosarcoma and Ewing sarcoma has yet been established, combination chemotherapy based on cisplatin, doxorubicin, and ifosfamide is mainly used; however, the efficacy is still uncertain. Prognosis of patients with advanced soft tissue and bone sarcomas is poor. Adriamycin-based combination chemotherapy results in a higher response rate than other combinations, ranging from 25 to $40 \%$, but median overall survival (OS) is only 8-12 months [1, 2]. Similarly, adult patients with metastatic bone sarcomas have a 5-year overall survival of less than $25 \%[3,4]$.

The anticancer agents gemcitabine and docetaxel are used to treat various malignant tumours, including nonsmall cell lung cancer and breast cancer. Combination chemotherapy with gemcitabine and docetaxel (GD) has been shown to be effective for metastatic leiomyosarcoma and other STS [5-10]. Recently, GD has been used for recurrent or refractory osteosarcoma and other bone sarcomas because several studies showed that this combination is effective [10-12]. Chemotherapeutic options for advanced sarcomas are limited. Recent options used in patients with advanced STS have included pazopanib, trabectedin, and eribulin. There are few options for second- or third-line therapy for refractory or metastatic bone sarcomas that has previously been treated with standard chemotherapy. If the effectiveness of GD is proven, it has the potential to result in new treatment options for advanced bone sarcomas and STS. Subtypes of sarcoma also respond differently to various chemotherapy drugs and treatment regimens. Future studies should analyse the response pattern of patients with different histologic subtypes of bone and soft tissue sarcoma. The aim of this Phase 2 study is to evaluate the efficacy and toxicity of GD in patients with advanced bone sarcomas and STS.

\section{Methods}

\section{Study objectives}

The primary aim of this study is to analyse the GD therapy effect on progression-free survival (PFS). The secondary objectives are to analyse treatment efficacy and safety by assessing response rate, tumour control rate, overall survival and adverse event rate.

The target sample size is based on expected response rate; however, the primary endpoint is defined as PFS because prolonging time to disease progression is important even if the response rate is less than expected.

\section{Design}

This is a Phase 2, single-arm, open-label study to investigate the efficacy and safety of combination chemotherapy with gemcitabine and docetaxel (GD) for advanced bone sarcomas and STS. Patients will receive gemcitabine $900 \mathrm{mg} / \mathrm{m}^{2}$ on Days 1 and 8 , and docetaxel $70 \mathrm{mg} /$ $\mathrm{m}^{2}$ on Day 8 , repeated at 21 days intervals until disease progression or other evidence of treatment failure. Patients will undergo computed tomography or magnetic resonance imaging and be evaluated for response after every second cycle using Response Evaluation Criteria in Solid Tumours (RECIST). The total duration of the study will be 5 years; all participants will attend for follow-up every 4-8 weeks after progression or treatment failure. A flowchart of the study design is presented in Fig. 1.

\section{Patient cohort}

The participants in this study will be recruited at Kobe University Hospital.

The inclusion criteria for this study are: (1) histopathologic diagnosis of primary malignant sarcoma of bone and soft tissue in extremity or trunk; (2) extremity or trunk bone sarcoma or STS presenting with advanced recurrence or metastatic disease diagnosed by biopsy as necessary; (3) previous received standard therapy for bone sarcoma or STS, or was unable to receive standard therapy; (4) age 1070 years at the time of enrolment; (5) measurable lesion(s); (6) performance status (PS) ECOG 0 or 1; (7) primary tumour was in the limbs or trunk; and (8) laboratory data no more than14 days prior to enrolment meeting the following criteria: (i) neutrophil count $>1,500 / \mathrm{mm}^{3}$; (ii) haemoglobin $>8.0 \mathrm{~g} / \mathrm{dL}$ (no blood transfusion within 14 days); (iii) platelet count $>100,000 / \mathrm{mm}^{3}$; (iv) total bilirubin 
1. 10-70 years old

2. Advanced bone and soft tissue sarcoma
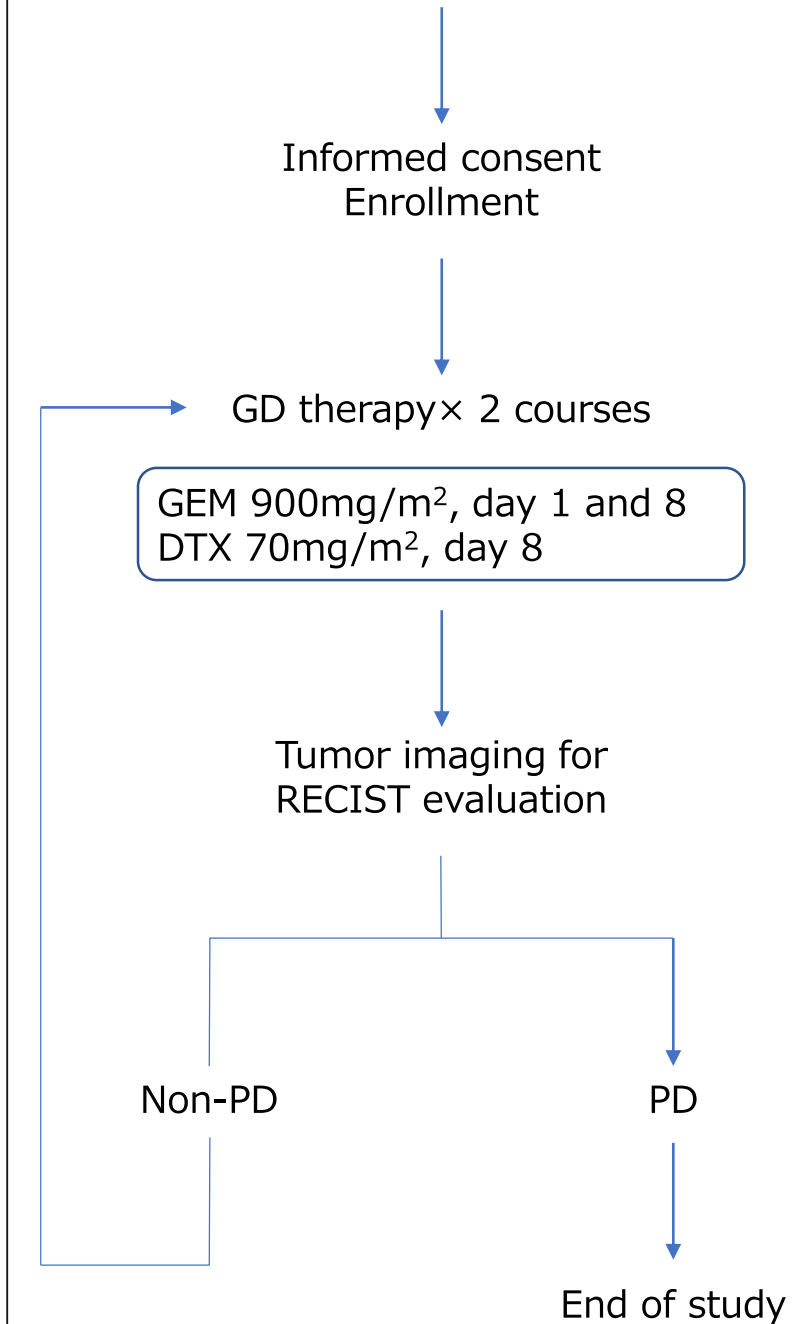

Fig. 1 Flowchart of Phase 2 study of gemcitabine and docetaxel combination chemotherapy for sarcomas

$<1.5 \mathrm{mg} / \mathrm{dL}$; (v) aspartate aminotransferase (glutamyl oxaloacetic transaminase) (AST [GOT]) < $100 \mathrm{IU} / \mathrm{L}$; (vi) alanine aminotransferase (glutamyl pyruvic transaminase) (ALT $[\mathrm{GPT}]$ ) $<100 \mathrm{IU} / \mathrm{L}$; (vii) creatinine $<1.5 \mathrm{mg} / \mathrm{dL}$; (viii) creatinine clearance (eGFR) $>60 \mathrm{~mL} / \mathrm{min}$; (ix) normal electrocardiogram no more than 28 days prior to enrolment; $(\mathrm{x})$ no interstitial pneumonia, pulmonary fibrosis, or pulmonary emphysema; and (xi) written informed consent obtained after patients has been given a written explanation of the study protocol. Patients meeting any of the following criteria will be excluded from this study: (1) active double cancers within 5 years (cured intraepithelial carcinoma and intramucosal carcinoma not included); (2) severe infection; (3) significant fever; (4) pregnancy or breastfeeding; (5) severe mental illness; (6) receiving continuous whole-body administration of steroids or other immunosuppressants; (7) unstable angina (within the past 3 months), myocardial infarction; (8) difficult-to-control hypertension; (9) difficultto-control diabetes; (10) positive hepatitis B antigen; and (11) the final decision to enrol will be up to each patient's physician.

\section{Target sample size and rationale}

A sample size of 16 will be required for a threshold response rate of $6 \%$ (based on the results of previous studies) and an expected response rate of $25 \%$, with a one-sided $\alpha$ of 0.1 and a $\beta$ of approximately 0.2. To allow for four dropouts, the target sample size of this study has been set to 20 . Assuming that four patients will be enrolled per year, the enrolment period has been set to 5 years.

\section{Study treatment}

\section{Drugs used}

The drugs will be administered in accordance with instructions in the package inserts.

Gemcitabine (Gemzar', Eli Lilly Oncology, Indianapolis IN, USA), Docetaxel (Taxotere ${ }^{\circ}$, Sanofi-Aventis, Paris, France)

The study patients will receive the marketed drugs that are available at the medical institution.

\section{Protocol treatment}

Protocol treatment should be started within 14 days after enrolment (day of enrolment counted as day zero; thus, up to the same day of the week after the next one is acceptable), and repeated in 3-week cycles until the criteria for treatment withdrawal (below) have been met. The drugs may be administered only after the participant has been confirmed to fulfil the following criteria within 3 days before Day 1 of each cycle: haemoglobin $\geq 8.0 \mathrm{~g} / \mathrm{dL}$, neutrophil count $\geq 1,000 / \mathrm{mm}^{3}$, platelet count $\geq 50,000 /$ $\mathrm{mm}^{3}$, AST $(\mathrm{GOT}) \leq 90 \mathrm{IU} / \mathrm{L}$, ALT $(\mathrm{GPT}) \leq 125 \mathrm{IU} / \mathrm{L}$ for male and $\leq 69 \mathrm{IU} / \mathrm{L}$ for female participants, creatinine $\leq 1.605 \mathrm{mg} / \mathrm{dL}$ for male and $\leq 1.185 \mathrm{mg} / \mathrm{dL}$ for female participants, grade $0-2$ fatigue, grade $0-2$ oedema limbs, grade $0-1$ diarrhoea, grade $0-1$ haematuria, grade $0-1$ mucositis oral, grade $0-1$ supraventricular tachycardia, grade $0-1$ ventricular arrhythmia, grade $0-1$ pneumonitis, and grade $0-1$ infection. The drugs may be administered only after the participant has been confirmed to fulfil the following criteria within 3 days before Day 8: haemoglobin $\geq 8.0 \mathrm{~g} / \mathrm{dL}$, neutrophil count $\geq 1,000 / \mathrm{mm}^{3}$, platelet count $\geq 50,000 / \mathrm{mm}^{3}$, AST $(\mathrm{GOT}) \leq 90 \mathrm{IU} / \mathrm{L}$, ALT $(\mathrm{GPT}) \leq 125 \mathrm{IU} / \mathrm{L}$ for male and $\leq 69 \mathrm{IU} / \mathrm{L}$ for female participants. The drugs should not be administered on Day 8 if the participant has Grade 2 or worse pneumonitis. If the above criteria are not fulfilled, protocol treatment should be withheld until they are met. If initiation of 
treatment is still considered contraindicated 15 days after Day 1 of that cycle, the patient will be classified as a "protocol treatment withdrawal".

\section{Criteria for dose reduction}

Doses will be reduced in participants with any toxicity meeting the criteria listed in Table 1 (adverse events for which a causal relationship to the protocol treatment cannot be ruled out). A $20 \%$ reduction in doses of gemcitabine and docetaxel is suggested. Dose modifications are allowed once, the dosage cannot be re-escalated. If toxicity does not abate during the monitoring period, administration of gemcitabine or docetaxel will be interrupted and/or the dose further reduced. The protocol treatment should be permanently

Table 1 Criteria for dose suspension or reduction

\begin{tabular}{|c|c|c|}
\hline Toxicity & Grade & Resumption plan \\
\hline 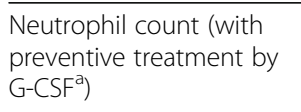 & $\begin{array}{l}\text { Grade } 4 \\
\text { (lasting for } 5 \\
\text { days or more) }\end{array}$ & $\begin{array}{l}\text { Preventive treatment by G- } \\
\text { CSF. }\end{array}$ \\
\hline $\begin{array}{l}\text { Neutrophil count } \\
\text { (without preventive } \\
\text { treatment by G-CSF) }\end{array}$ & $\begin{array}{l}\text { Grade } 4 \\
\text { (lasting for } 5 \\
\text { days or more) }\end{array}$ & \multirow{5}{*}{$\begin{array}{l}\text { Reduced dose of } 720 \mathrm{mg} / \\
\mathrm{m} 2 \text { of GEM } \\
\text { of DTX } 55 \mathrm{mg} / \mathrm{m} 2 \\
\text { then } 570 \mathrm{mg} / \mathrm{m} 2 \text { of GEM } \\
\text { and } 44 \mathrm{mg} / \mathrm{m} 2 \text { of DTX } \\
\text { (second occurrence). }\end{array}$} \\
\hline Diarrhea & Grade 3 & \\
\hline Mucositis oral & Grade 3 & \\
\hline Infection & Grade 3 & \\
\hline \multirow[t]{2}{*}{ Pneumonitis } & Grade 1 & \\
\hline & Grade 2 & $\begin{array}{l}\text { Discontinue protocol } \\
\text { treatment. }\end{array}$ \\
\hline \multirow[t]{2}{*}{ Neuropathy } & Grade 2 & $\begin{array}{l}\text { Reduced dose of } 720 \mathrm{mg} / \\
\mathrm{m} 2 \text { of GEM and } 55 \mathrm{mg} / \mathrm{m} 2 \text { of } \\
\text { DTX (first occurrence), then } \\
570 \mathrm{mg} / \mathrm{m} 2 \text { of GEM and } \\
44 \mathrm{mg} / \mathrm{m} 2 \text { of DTX (second } \\
\text { occurrence). }\end{array}$ \\
\hline & Grade 3 & \multirow{11}{*}{$\begin{array}{l}\text { Discontinue protocol } \\
\text { treatment. }\end{array}$} \\
\hline Creatinine & Grade 2-4 & \\
\hline $\begin{array}{l}\text { Supraventricular } \\
\text { tachycardia }\end{array}$ & $\begin{array}{l}\text { Grade } 2 \text { (two } \\
\text { times), Grade } 3\end{array}$ & \\
\hline Atrial arrhythmia & $\begin{array}{l}\text { Grade } 2 \text { (two } \\
\text { times), Grade } 3\end{array}$ & \\
\hline $\begin{array}{l}\text { Left ventriclar contractile } \\
\text { dysfunction }\end{array}$ & $\begin{array}{l}\text { Grade } 2 \text { (two } \\
\text { times), Grade } 3\end{array}$ & \\
\hline Vertigo/Dizziness & Grade 2-3 & \\
\hline $\begin{array}{l}\text { Depressed level of } \\
\text { consciousness }\end{array}$ & Grade 2-3 & \\
\hline Seizure & Grade 2-3 & \\
\hline Leukoencephalopathy & Grade $2-3$ & \\
\hline $\begin{array}{l}\text { Non-hematological } \\
\text { toxicity }\end{array}$ & Grade 4 & \\
\hline \multicolumn{2}{|c|}{$\begin{array}{l}\text { Any adverse events which occurred with } \\
\text { dose of } 570 \mathrm{mg} / \mathrm{m} 2 \text { of GEM and } 44 \mathrm{mg} / \\
\mathrm{m} 2 \text { of DTX. }\end{array}$} & \\
\hline
\end{tabular}

${ }^{\mathrm{a}} G$-CSF Granulocyte colony stimulating factor, GEM Gemcitabine, DTX Docetaxel discontinued for any haematological or non-haematological toxicity requiring an interruption of $\geq 14$ days.

\section{Outcomes \\ Primary endpoint}

The primary endpoint is progression-free survival (PFS), calculated as time from enrolment until first objective documentation of disease progression, treatment failure, or death from any cause.

\section{Secondary endpoints}

Secondary endpoints are objective tumour response, calculated as overall response rate and disease control rate, along with time to onset of response. Assessment of response and progression is based on RECIST version 1.1 [13]. Overall survival (OS) will be calculated as time from enrolment until death from any cause. Safety and tolerability will be assessed continuously throughout the study. Adverse events will be graded using the National Cancer Institute Common Terminology Criteria for Adverse Events version 4.0 (CTCAE v4.0) [14]. The worst grade of an event during the observation period will be used to denote the severity of that adverse event. Primary and secondary prophylaxis of neutropenia will be routinely assessed and documented in each cycle. Repeated physical examinations will be conducted throughout the study period (consisting of the treatment and post-treatment follow-up periods), including assessment of vital signs and haematological and chemical laboratory tests.

\section{Statistical analysis}

The per protocol set (PPS) will consist of the full analysis of subjects enrolled in this study, excluding those lacking baseline data or with any significant protocol violations involving the study method or concomitant therapy. The safety analysis set will consist of all patients enrolled in this study who received at least one dose of the study drugs. The primary analysis of PFS will be performed on the PPS 1 year after the end of the enrolment period. A confirmatory analysis of all secondary endpoints will be performed at the end of the follow-up period. KaplanMeier curves will be used to analyse PFS, OS, and median survival time and $95 \%$ confidence intervals for point estimates will be calculated using Greenwood's formula. The safety endpoint of this study is the frequency of adverse events. No interim analysis is planned.

\section{Discussion}

Bone sarcomas and STS are rare and heterogeneous malignant tumours that account for approximately $1 \%$ of all malignant tumours. Osteosarcoma, the most common primary malignant bone tumour, is treated by a standard chemotherapy regimen including high-dose methotrexate, 
cisplatin, and doxorubicin. Ifosfamide is also an established active agent for osteosarcoma. Ewing sarcoma, a malignant, small round-cell tumour of bone and soft tissue, is treated by multi-agent chemotherapy schedules with vincristine, doxorubicin, and cyclophosphamide (VDC)/ifosfamide and etoposide (IE). Because other malignant primary bone tumours are extremely rare, there is no standard chemotherapy for them and they are treated with regimens similar to those for osteosarcoma. For STS, the mainstream treatment has been various combinations incorporating doxorubicin and ifosfamide. Recently, the agents pazopanib, trabectedin, and eribulin were approved, providing treatment options for second-line or later therapy for patients with STS. However, no optimal therapeutic strategies for histologic subtypes of advanced STS have yet been established.

This study aims to evaluate the efficacy and safety of combination therapy with GD for bone sarcoma and STS. If GD therapy proves to be acceptable, we can provide it as second, third or later lines for sarcoma patients (especially for bone sarcomas). In the future, the role of these treatments, including GD therapy, in specific subtypes of sarcoma may be further clarified.

Limitations of this study include that the sample size is small and that patients with all subtypes of sarcoma will be enrolled, including both bone and soft tissue lesions. A multi-institutional study is needed to achieve a larger sample size and investigate the efficacy of GD therapy for individual subtypes in Japan.

\section{Additional files}

Additional file 1: Data manegement and informed consent procedure (DOCX $23 \mathrm{~kb}$ )

Additional file 2: Procedure for implementation of study monitoring. (DOCX $19 \mathrm{~kb})$

\section{Abbreviations \\ ALT (GPT): Alanine aminotransferase (glutamyl pyruvic transaminase); AST (GOT): Aspartate aminotransferase (glutamyl oxaloacetic transaminase); CTCAE: Common Terminology Criteria for Adverse Events; ECOG: Eastern Cooperative Oncology Group; eGFR: Estimate glomerular filtration rate; GD: Gemcitabine and docetaxel; PFS: Progression-free survival; RECIST: Response Evaluation Criteria in Solid Tumours; STS: Soft tissue sarcoma}

\section{Acknowledgements}

We thank Libby Cone, MD, MA, and Trish Reynolds, MBBS, FRACP, from Edanz Group Japan (https://www.edanzediting.com/ac) for editing drafts of this manuscript.

\section{Authors' contributions}

$\mathrm{HH}$ participated in study design, and will participate in conduct of the study and analysis of data, and is the corresponding author. TK will participate in conduct of the study, data collection, and analysis of data. NF, YK, TT, SF and KK will participate in data collection and patient management. KN participated in study design. RK participated in study design and initiation. TA participated in study design and manuscript revision, and will participate in analysis. All authors have approved the final version of the manuscript, and agree to be accountable for all aspects of the work in ensuring that questions related to the accuracy or integrity of any part of the work are appropriately investigated and resolved.

\section{Funding}

No funding has been received specifically for this study.

\section{Availability of data and materials}

The study results, data, and intellectual property rights from this study will belong to the Department of Orthopaedic Surgery of Kobe University Hospital. Specific aspects of handling and distribution will be decided after discussion. Whether the intellectual property will be owned personally by the study representative, principal investigator at the research institution, or the Department of Orthopaedic Surgery will be determined according to the rules of the research institution. Data management and informed consent procedure are indicated in a separate file (Additional file 1). Furthermore, procedure for implementation of this study monitoring is indicated in a separate file (Additional file 2).

\section{Ethics approval and consent to participate}

This study will be conducted in compliance with the Declaration of Helsinki; the Ethical Guidelines for Medical and Health Research involving Human Subjects; and Kobe University Conflicts of Interest Management Guideline. The study protocol (protocol version 1.1, 28 February 2018) was reviewed and approved by Kobe University Clinical Research Ethics Committee. Given the age distribution of the target disease, this study would not be feasible without enrolment of paediatric patients; thus, such patients will be included in this study and written consent of their legal guardians will also be obtained.

Consent for publication

Not applicable.

\section{Competing interests}

The authors declare that they have no competing interests.

\section{Author details}

${ }^{1}$ Department of Orthopaedic Surgery, Kobe University Graduate School of Medicine, 7-5-1 Kusunoki-cho, Chuo-ku, Kobe 650-0017, Japan. ²Division of Orthopaedic Surgery, Kobe University International Clinical Cancer Research Centre, 1-5-1 Minatojimaminami-cho, Chuo-ku, Kobe 650-0047, Japan.

${ }^{3}$ Department of Rehabilitation Science, Kobe University Graduate School of Health Sciences, 7-10-2 Tomogaoka, Suma-ku, Kobe 654-0142, Japan.

Received: 30 November 2018 Accepted: 11 July 2019

Published online: 23 July 2019

\section{References}

1. Edmonson JH, Ryan LM, Falkson Cl, Hicks DG, Blum RH. Phase II study of Ifosfamide+doxorubicin in patients with advanced synovial sarcomas (E1793): a trial of the eastern cooperative oncology group. Sarcoma. 2003;7: 9-11

2. Frustaci S, Foladore S, Buonadonna A, De Paoli A, Crivellari D, Carbone A, Sorio R, Morassut S, Monfardini S. Epirubicin and ifosfamide in advanced soft tissue sarcomas. Ann Oncol. 1993;4:669-72.

3. Geller DS, Gorlick R. Osteosarcoma: a review of diagnosis, management, and treatment strategies. Clin Adv Hematol Oncol. 2010;8:705-18.

4. Verma V, Denniston KA, Lin CJ, Lin C. A comparison of pediatric vs. adult patients with the Ewing sarcoma family of tumors. Front Oncol. 2017;8:82: 1-9.

5. Hensley ML, Maki R, Venkatraman E, Geller G, Lovegren M, Aghajanian C, Sabbatini P, Tong W, Barakat R, Spriggs DR. Gemcitabine and docetaxel in patients with unresectable leiomyosarcoma: results of a phase II trial. J Clin Oncol. 2002:20:2824-31.

6. Maki RG, Wathen JK, Patel SR, Priebat DA, Okuno SH, Samuels B, Fanucchi M, Harmon DC, Schuetze SM, Reinke D, Thall PF, Benjamin RS, Baker LH, Hensley ML. Randomized phase II study of gemcitabine and docetaxel compared with gemcitabine alone in patients with metastatic soft tissue sarcomas: results of sarcoma alliance for research through collaboration study 002 [corrected]. J Clin Oncol. 2007;25:2755-63.

7. Bay JO, Ray-Coquard I, Fayette J, Leyvraz S, Cherix S, Piperno-Neumann S, Chevreau C, Isambert N, Brain E, Emile G, Le Cesne A, Cioffi A, Kwiatkowski 
F, Coindre JM, Bui NB, Peyrade F, Penel N, Blay JY, Groupe Sarcome Français. Docetaxel and gemcitabine combination in 133 advanced soft-tissue sarcomas: a retrospective analysis. Int J Cancer. 2006;119:706-11.

8. Leu KM, Ostruszka LJ, Shewach D, Zalupski M, Sondak V, Biermann JS, Lee JS, Couwlier C, Palazzolo K, Baker LH. Laboratory and clinical evidence of synergistic cytotoxicity of sequential treatment with gemcitabine followed by docetaxel in the treatment of sarcoma. J Clin Oncol. 2004;22:1706-12.

9. Lee EM, Rha SY, Lee J, Park KH, Ahn JH. Phase II study of weekly docetaxel and fixed dose rate gemcitabine in patients with previously treated advanced soft tissue and bone sarcoma. Cancer Chemother Pharmacol. 2012;69:635-42.

10. Lee HY, Shin SJ, Kim HS, Hong SJ, Han JW, Lim ST, Roh JK, Rha SY. Weekly gemcitabine and docetaxel in refractory soft tissue sarcoma: a retrospective analysis. Cancer Res Treat. 2012;44:43-9.

11. Lee JA, Jeon DG, Cho WH, Song WS, Yoon HS, Park HJ, Park BK, Choi HS, Ahn HS, Lee JW, Yoo KH, Sung KW, Koo HH, Kang HJ, Park KD, Shin HY, Koh KN, Im HJ, Seo JJ, Lim YJ, Baek HJ, Kook H. Higher gemcitabine dose was associated with better outcome of osteosarcoma patients receiving gemcitabinedocetaxel chemotherapy. Pediatr Blood Cancer. 2016;63:1552-6.

12. Palmerini E, Jones RL, Marchesi E, Paioli A, Cesari M, Longhi A, Meazza C, Coccoli L, Fagioli F, Asaftei S, Grignani G, Tamburini A, Pollack SM, Picci P, Ferrari S. Gemcitabine and docetaxel in relapsed and unresectable highgrade osteosarcoma and spindle cell sarcoma of bone. BMC Cancer. 2016; 20:280.

13. Eisenhauer EA, Therasse P, Bogaerts J, Schwartz LH, Sargent D, Ford R, Dancey J, Arbuck S, Gwyther S, Mooney M, Rubinstein L, Shankar L, Dodd L, Kaplan R, Lacombe D, Verweij J. New response evaluation criteria in solid tumours: revised RECIST quideline (version 1.1). Eur J Cancer. 2009;45:228-47.

14. Common Terminology Criteria for Adverse Events (CTCAE) Version 4.0 Japanese translation version (CTCAE v4.0 - JCOG). URL: http://ctep.cancer. gov/protocolDevelopment/electronic_applications/ctc.htm\#ctc_40.

\section{Publisher's Note}

Springer Nature remains neutral with regard to jurisdictional claims in published maps and institutional affiliations.

Ready to submit your research? Choose BMC and benefit from:

- fast, convenient online submission

- thorough peer review by experienced researchers in your field

- rapid publication on acceptance

- support for research data, including large and complex data types

- gold Open Access which fosters wider collaboration and increased citations

- maximum visibility for your research: over $100 \mathrm{M}$ website views per year

At $\mathrm{BMC}$, research is always in progress.

Learn more biomedcentral.com/submissions 